\title{
Willingness to Learn: Cultural Intelligence Effect on Perspective Taking and Multicultural Creativity
}

\author{
Diana R. Castañeda ${ }^{1}$, Aihua Huang ${ }^{1}$ \& Ahuitz R. Avalos ${ }^{2}$ \\ ${ }^{1}$ School of Business Administration, South China University of Technology, Guangzhou, China \\ ${ }^{2}$ School of Economics and Management, Chongqing University of Posts and Telecommunications, Chongqing, \\ China \\ Correspondence: Diana R. Castañeda, School of Business Administration, South China Uni versity of Technology, \\ Guangzhou, Guangdong, China, ZP 510641.
}

Received: December 6, 2017

Accepted: January 4, 2018

Online Published: January 8, 2018

doi:10.5539/ibr.v11n2p116

URL: https://doi.org/10.5539/ibr.v11n2p116

\begin{abstract}
Technological development has intensified interconnectivity in the global sphere creating highly diverse markets and workplaces making increasingly challenging for contemporary organizations to manage culturally diverse environments while benefiting from them. Hence, fostering employees' ability to produce both novel and useful ideas within cross-cultural environments has gained enormous importance. This research attempts to better understand the relationship between cultural intelligence (CQ), perspective taking, and multicultural creativity. Data analysis from a causal, descriptive, non-experimental network survey, containing a remote associates test, supports the proposed theoretical framework in which cultural intelligence has an influence on the relationship between perspective taking and the individuals' capability of drawing upon knowledge from distinct cultures. The results of the study show that two dimensions of cultural intelligence, motivational CQ and behavioral CQ, positively influence individuals' multicultural creativity. These findings have positive implications when facing the urgent necessity of cross-cultural collaboration.
\end{abstract}

Keywords: creativity, cultural intelligence, multicultural environment, multicultural experience, multicultural creativity, perspective taking

\section{Introduction}

Due to technological developments as well as pressure from globalization processes, workplaces have become more culturally diverse and interdependence has greatly contributed to diversify markets since organizations have to deal with stakeholders from diverse cultural backgrounds. Globalization has also swelled the idea of belonging to a world which is systematic and where we all share common concerns, such as climate change. This unprecedented facet of multiculturalism as well as the increased interconnectivity among individuals, make organizations more dependable on employees' creative ideas, especially those that come from multicultural environments since they can particularly better respond to the complexity of present-day markets as well as enrich the organization's knowledge base. For instance, the Global Innovation Index of 2016 revealed that innovations call for more international collaboration, not only to enhance creativity but also to expand the scope of innovation (Cornell University, INSEAD, \& WIPO, 2016).

Amabile (1983) defined creativity as the development of ideas that are both novel and useful. However, this study focuses on creativity that requires drawing on knowledge from various cultures, which is known as multicultural creativity (Chua, 2013). Indeed, scholars have proven that a multiculturally diverse environment has a positive influence on creativity (Leung, Maddux, Galinsky, \& Chiu, 2008; Maddux, Adam, \& Galinsky, 2010). This type of creativity, as it includes generated knowledge from distinct cultures, has achieved a certain complexity degree that responds to the inherent necessities of multicultural environments as wells as to the demands of the current worldwide context.

However, it is imperative to note that intercultural work environments do not always lead to the creation of novel and useful ideas and even sometimes obstruct the creative process (Chua, 2013). This is mainly because tensions and conflicts unavoidably take place as organizations become more culturally diverse (Jehn \& Mannix, 2001). For instance, scholars have demonstrated that experiencing indirect cross-cultural tensions and conflicts in a 
direct social environment strengthens ideas of cultural incompatibility and stereotypes, hence it alters individuals' capacity to make use of knowledge from various cultures (Chua, 2013). Researchers have not yet found how to mitigate this negative effect of ambient cultural disharmony on creativity.

An initial approach in the literature of creativity aiming to enhance the creative process has studied three key factors: climate, trust, and knowledge sharing (Černe, Nerstad, Dysvik, \& Škerlavaj, 2014; Grant \& Berry, 2011). Nonetheless, all these studies have not considered the role of multicultural environments thus far. A more approximate approach in the research about diversity has studied diverse teams, where scholars have reported that work teams are enriched by their diversity (Hoever, Van Knippenberg, Van Ginkel, \& Barkema, 2012).

A growing body of studies being conducted around the world suggests that the current global conditions demand to improve individuals' competence to function adequately when they face cross-national assignments, which take place in multicultural situations, ethnically-distinct environments or organizations that differ in their corporate culture. This ability is known as Cultural Intelligence (CQ) (Bhagat, 2006; Livermore, Ang, \& Van Dyne, 2010). Cultural intelligence enables individuals not only to adapt to a new cultural environment but also to absorb expertise from it to design a strategy in order to perform in a competent manner. Therefore, its relevance lies on the fact that, as well as emotional intelligence (EQ) and intelligence quotient (IQ) (Daher, 2015), it is a competence which can be cultivated (Erez et al., 2013). Cultural intelligence has the power to determine the performance success or failure of an indi vidual (Ang et al., 2007; Bücker, Furrer, Poutsma, \& Buyens, 2014; Ng, Ang, \& Van Dyne, 2011) in a certain environment. This plays a pivotal role to excel in today's work environment.

Cultural intelligence is comprised of four dimensions: metacognitive, cognitive, motivational, and behavioral. Metacognitive CQ refers to individuals' capability to strategize in a cross-cultural environment. That is, capabilities such as planning, monitoring, and revising mental models of divergent cultural standards are used to increase awareness of other's cultural preferences. Cognitive CQ denotes the well understanding of other's cultures norms and differences. This dimension is nurtured by knowledge gained through education or firsthand experiences. Motivational CQ is the level of interest in adjusting to multiculturality. When this dimension is displayed, individuals expend energy to learn and perform in cross-cultural situations. Finally, behavioral CQ is the ability to adapt verbal and nonverbal language to interact properly with people from diverse cultural backgrounds. Individuals with high behavioral CQ possess chameleon-like demeanors that involve using culturally fitting words and nonverbal expressions (Ang et al., 2007; Van Dyne, Ang, \& Koh, 2008). Furthermore, another approach in the personality literature performed a study about the Big 5 personality traits where researchers found that all four dimensions of CQ show a positive relationship with openness to experience, which at the same time was proven to have a significant relationship with creativity when individuals possess a high extrinsic motivation (Ang \& Van Dyne, 2006).

Why is CQ related to creativity? Once individuals have developed the skills to communicate with confidence in a multicultural setting, the acquired knowledge will allow them to learn from their surroundings. Moreover, the willingness to have culturally unfamiliar experiences will facilitate multinational encounters.

This paper contends that cultural intelligence can serve as a path to enrich from a multicultural environment, regardless of its conditions, and has a positive impact on the creative ability of individuals. It proposes that individuals with a superior level of cultural intelligence can not only more easily associate knowledge from different cultures, but also have a more effective communication to take other people's perspectives. The purpose of this research is to respond to the literature gap regarding CQ and its effect on creativity. Additionally, this article suggests that cultural intelligence has a positive association with perspective taking. Individuals can benefit from this as the possibilities to face conflicts related to prejudices, stereotypes, and a hermetic attitude are diminished. Cultivation of CQ can provide individuals with the confidence, strategies, and skills required to adopt openness to learn from people with dissimilar cultural backgrounds and be part of a more novel and refined environment.

\subsection{Hypotheses Statement}

\section{The potential advantage of mul ticulturality}

Cultural diversity is composed of plurality and authenticity of a set of meanings, values, and beliefs that determine thinking and behavior. Despite the importance of innovation for social and economic progress, (Vovchenko, Ivano va, Kostoglodova, Otrishko, \& Dzhu, 2016) today's global context makes innovation more dependent on cross-border collaboration (Cornell University et al., 2016). Undoubtedly, the world faces many more complex challenges that demand the construction of new knowledge resulting of cultural exchange to get more enriching answers. It can be understood that cultural diversity is a major driver for development that fosters 
economic growth as well as aids to refine ourselves intellectually. Consequently, diversity becomes a way to address the expected improvement in everyone's life.

\section{The complexity of cul tural diversity}

Culturally diverse environments can have several benefits to individuals who are exposed to them. For instance, scholars have studied how an intercultural ambient enhances creativity (Leung et al., 2008; Maddux et al., 2010). This kind of atmosphere is highly rich in views and it presents an extraordinary opportunity for learning; however, the convergence of plurality is divergent in nature. Therefore, to achieve harmony in such environments as well as maintain its authenticity and disparity is an arduous task. For example, scholars have also discovered that creativity in that kind of environments is not always achieved (Chua, 2013).

The lack of uniformity and homogeneity when organizations are cultural diverse makes tension and conflicts inevitably present (Jehn \& Mannix, 2001). Accordingly, to accomplish multicultural creativity in a cultural environment is a complex challenge that requires more than only having cultural diversity.

\section{Cul tural intelligence on creativity}

This article moots that, irrespective of the characteristics of their environment, individuals can de velop the four dimensions of cultural intelligence to take advantage of it since their level of CQ allows them to express sympathy and expand their perspectives instead of limiting them (Chen \& Lin, 2013). As it is related to openness to experience (Ang \& Van Dyne, 2006), cultural intelligence strengthens empathy among individuals, hence enables them to relate ideas from different frameworks. Indi viduals with elevated levels of CQ are able to learn from others as well as cooperate and integrate other people's perspectives into their own judgment.

Furthermore, this research draws upon perspective taking which is defined as cognitive process where, in order to understand others' needs, thoughts, values, and preferences, individuals tend to accept other's points of view and at the same time they are able to see the value of other's ideas (Grant \& Berry, 2011). The four dimensions of CQ in a multicultural environment strengthen the cognitive process of perspectives taking, not only in the disposition or motivation that individuals possess, but also in their ability to understand their environment and communicate effectively facilitating the free exchange of ideas.

Perspective taking together with cultural intelligence allows individuals to communicate effectively with people from diverse cultural backgrounds and learn from them. Moreover, perspective taking reduces the chances of conforming to stereotypes (Galinsky \& Moskowitz, 2000) and is associated with less person-oriented conflict perceptions (Sessa, 1996). Scholars have also proven that perspective taking has more possibilities to enhance creativity not only because it fosters knowledge exchange (Grant \& Berry, 2011), but supports the integration of different ideas and their extensive analysis. The analysis of plural ideas may drive the combination of them (Hargadon \& Bechky, 2006).

The following two hypotheses of this research propose that individuals with a higher level of cultural intelligence are more able to engage in a perspective taking cognitive process.

Hypothesis 1. Cultural intelligence is positively associated with perspective taking

Hypothesis 2. Cultural intelligence strengthens the relationship between perspective taking and multicultural creativity

Finally, this article asserts that when individuals develop the four capabilities of cultural intelligence have a greater opportunity to learn from others, and the knowledge obtained may have a positive impact on their creativity output when they are required to draw on information from various cultures. Within the scope of cross-cultural collaboration, the convergence of the disparity of ideas is based on the ability to know how to listen and learn from each other.

\section{Method}

\subsection{Sample Selection}

To participate in this study, respondents had to meet one of the following criteria (1) have pre viously moved to a country different from their country of origin for studying or working (2) currently live in a country different from their country of origin for studying or working (3) are currently located in their country of origin but working or studying in an immediate environment which is multiculturally diverse. In all cases, English was the language of instruction in their university or the primary language of communication at their workplace. When compared to working or studying abroad, vacations have an inferior contribution to cross-cultural learning (Bücker, Furrer, \& Lin, 2015), thus individuals who had only intercultural experiences derived from international tourism were not considered in the sample selection. 


\subsection{Procedure}

The authors distributed a survey online adopting the snowball sampling technique (Goodman, 1961). The participants were invited to forward the survey link to other people they knew that matched the established criteria. This was made to avoid distance and time constraints of the survey administration and to diversify the cultural background of the respondents by reaching people in other countries. At a completion rate of $67.05 \%$, empirical data were collected from 116 respondents. The survey comprised a total of four components; participants were given a maximum of thirty minutes to complete it. The first section collected demographic data such as country of origin and country of current residence, and their own assessment of how culturally diverse they perceived their direct social environment. The two following parts of the survey included items from perspective taking (Davis, 1983) and cultural intelligence scales respectively, and the last part of the survey contained a multicultural Remote Associates Test (RAT) (Chua, 2013). The first three parts of the survey were administered in English and to avoid any misconception or language barrier that may affect the multicultural RAT performance, a simple translation of the trio of words into Spanish, Chinese, and French was provided in the fourth section. Translations were selected according to sample's convenience.

\subsection{Measures}

\section{Multicultural environment}

Since the survey was only administered to people who have previous or current experience working or studying in a country different from their country of origin, and those who, without leaving their country of origin, are situated in a multiculturally diverse environment, such as the International Students Office of a university with significant cross-cultural population, respondents were asked to assess their own direct social surroundings from $1=$ "Not at all multiculturally diverse" to $5=$ "Highly multiculturally diverse".

\section{Multicultural experience}

Participants were asked to indicate the total amount of years that they had spent outside their country of origin at the time of completing the survey, without considering whether their experience was accumulated uninterruptedly or not.

\section{Perspective taking}

Participants were asked to answer seven questions on perspective taking that used a se ven-point Likert scale $(1=$ "Strongly disagree", and 7 = "Strongly agree"). These questions were adapted from Davis (1983). Sample items include "When in a multicultural environment, before criticizing somebody I try to imagine how I would feel if I were in his/her place", and "I sometimes try to understand people from distinct cultural groups better by imagining how things look from their perspective". With the purpose of avoiding acquiescence bias and improving the participants' understanding of the questions, some of the items were phrased in reverse.

\section{Cul tural Intelligence (CQ)}

This article adapted a twenty-item Likert-type scale ( 1 = "Strongly disagree", and 7 = "Strongly agree") developed by Bücker et al. (2015) to measure the four dimensions of cultural intelligence; Meta-cognitive CQ, Motivational CQ, Cognitive CQ, and behavioral CQ. To avoid acquiescence bias and improving the participants' understanding of the questions, some of the items were also phrased in reverse.

A reliability analysis for these adapted scales was carried out (Cronbach's $\alpha=0.82$ ). All 27 items appeared to be worthy of retention, resulting in a decrease in the alpha value if deleted. The one exception to this was item 5, which would maintain alpha at the same value. Hence, none of the items were removed.

\section{Multicultural creativity}

Respondents of the survey were asked to complete a multicultural Remote Associates Test (RAT), which is a cross-cultural version of a widely used tool in psychological and organizations research to assess the ability of individuals to make connections between seemingly dissimilar concepts. The multicultural RAT consists of 12 trios of words that if mingled with a fourth word denote a cross-cultural concept. For instance, the trio of words Forbidden, angels and Quebec when put together with the word city, allude to the Forbidden City in Beijing, Los Angeles, California, and the Canadian city of Quebec. As shown in pre vious research, individuals who possess a high score in the multicultural RAT have the capability to make associations between multiculturally diverse concepts. This test provides confidence about its validity since it was found to be positively associated with the combination of ideas which belong to different cultural backgrounds when performing creative tasks (Chua, 2013). 


\section{Results}

\subsection{Demographic Profile of the Sample}

After eliminating two surveys which participants answered randomly and had missing data respectively, the final sample analyzed consisted of 114 respondents ( $61.4 \%$ male; $73.7 \%$ between 25 and 34 years of age) from 32 countries of origin residing in 26 countries. The majority were employed full-time (46.5\%) and $46 \%$ were living outside their country of origin at the time of completing the survey.

\subsection{Statistics and Data Analysis}

Table 1 exhibits the descriptive statistics and correlations for the variables in this study. All correlations were positively associated and 20 out of 28 were statistically significant. After finding an expected positive, although non-significant, relationship between individuals' cultural intelligence and their multicultural experience (expressed in years spent outside their country of origin), it was observed that perspective taking showed a considerable positive correlation $(\mathrm{r}=.55, \mathrm{p}<.01)$ with cultural intelligence as a whole and with each of its four dimensions. This confirms the idea that individuals who cultivate the four dimensions of CQ are more likely to understand others' viewpoints and provides evidence to support Hypothesis 1.

Table 1. Descriptive Statistics and Correlations

\begin{tabular}{|c|c|c|c|c|c|c|c|c|c|c|c|c|}
\hline Variable & Mean & s.d. & Min. & Max. & 1 & 2 & 3 & 4 & 5 & 6 & 7 & 8 \\
\hline 1. Perspective Taking & 37.22 & 5.81 & 18 & 49 & & & & & & & & \\
\hline 2. Metacognitive CQ & 20.46 & 3.63 & 9 & 28 & $0.40^{* *}$ & & & & & & & \\
\hline 3. Cognitive CQ & 29.00 & 5.99 & 11 & 40 & $0.36^{* *}$ & $0.40^{* * *}$ & & & & & & \\
\hline 4. Motivational CQ & 27.94 & 4.92 & 15 & 35 & $0.41^{* *}$ & $0.33^{* *}$ & $0.41^{* *}$ & & & & & \\
\hline 5. Behavioral CQ & 23.27 & 5.19 & 11 & 35 & $0.42^{* *}$ & $0.35^{* *}$ & $0.37^{* *}$ & 0.16 & & & & \\
\hline 6. Cultural Intelligence & 100.67 & 14.06 & 58 & 131 & $0.55^{* *}$ & $0.68^{* * *}$ & $0.81^{* *}$ & $0.67^{* *}$ & $0.67^{* *}$ & & & \\
\hline $\begin{array}{l}\text { 7. Multicultural } \\
\text { Creativity }\end{array}$ & 4.21 & 3.30 & 0 & 12 & 0.04 & 0.05 & 0.08 & $0.21^{*}$ & $0.25^{*}$ & $0.21^{*}$ & & \\
\hline $\begin{array}{l}\text { 8. Multicultural } \\
\text { experience in years }\end{array}$ & 3.45 & 3.00 & 0 & 16 & 0.09 & 0.14 & $0.29^{* *}$ & 0.22 & 0.15 & $0.29^{* *}$ & 0.17 & \\
\hline
\end{tabular}

$\mathrm{n}=114^{* *} \mathrm{p}<.01 * \mathrm{p}<.05$

To test Hypothesis 2, a regression analysis was conducted in SPSS (version 24). Table 2 showed that the overall model fit, resulting in $R^{2}=0.33$ ( $<<.01$ ), improved when the four dimensions of cultural intelligence where added to the regression predicting multicultural creativity. It was also observed that motivational $C Q(b=0.17$, $\mathrm{SE}=.06, \mathrm{p}<0.5)$ and behavioral $\mathrm{CQ}(\mathrm{b}=0.15, \mathrm{SE}=.07, \mathrm{p}<0.5)$ had a particular effect on the relationship between perspective taking and multicultural creativity. Two adjusted regression curves illustrate this phenomenon (see Figures 1 and 2). To better understand this effect, an analysis of the mediating effect of those two variables was conducted using PROCESS macro (version 2.16) for SPSS. The results showed that perspective taking was a significant predictor of behavioral $\mathrm{CQ}(\mathrm{b}=.42, \mathrm{SE}=.08, \mathrm{p}<.05)$ and motivational $\mathrm{CQ}$ $(\mathrm{b}=.41, \mathrm{SE}=.08, \mathrm{p}<.05)$. Moreover, both behavioral CQ $(\mathrm{b}=.29, \mathrm{SE}=.11, \mathrm{p}<.05)$ and motivational $\mathrm{CQ}(\mathrm{b}$ $=.23, \mathrm{SE}=.09, \mathrm{p}<.05)$ were signific ant predictors of multicultural creativity. Finally, perspective taking $(\mathrm{b}=$ $-0.17, \mathrm{SE}=.10, \mathrm{p}>.05)$ was no longer a significant predictor of multicultural creativity after controlling for both mediators (see Figure 3). 
Table 2. Multiple Regression Results

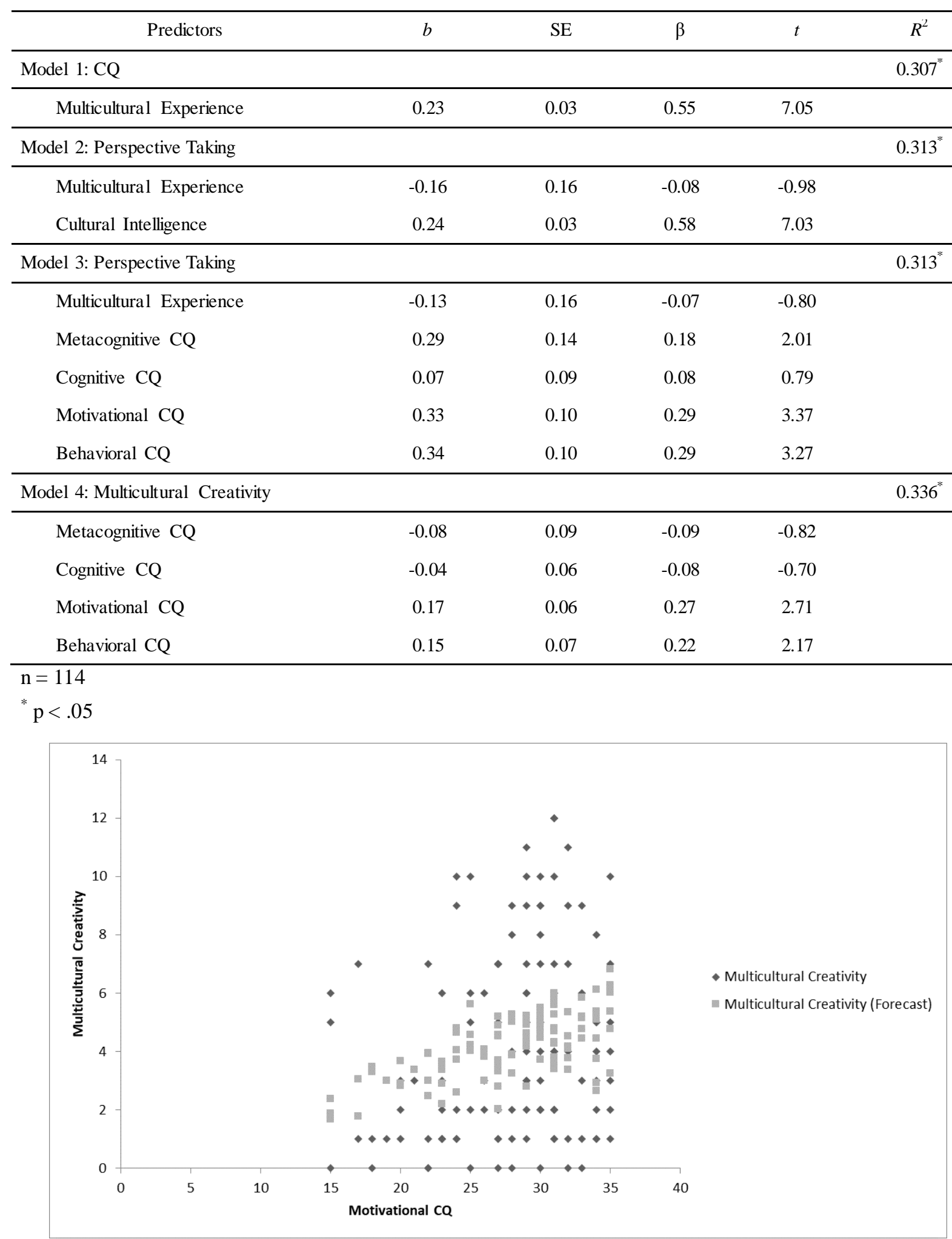

Figure 1. Adjusted Regression Curve for Motivational CQ 


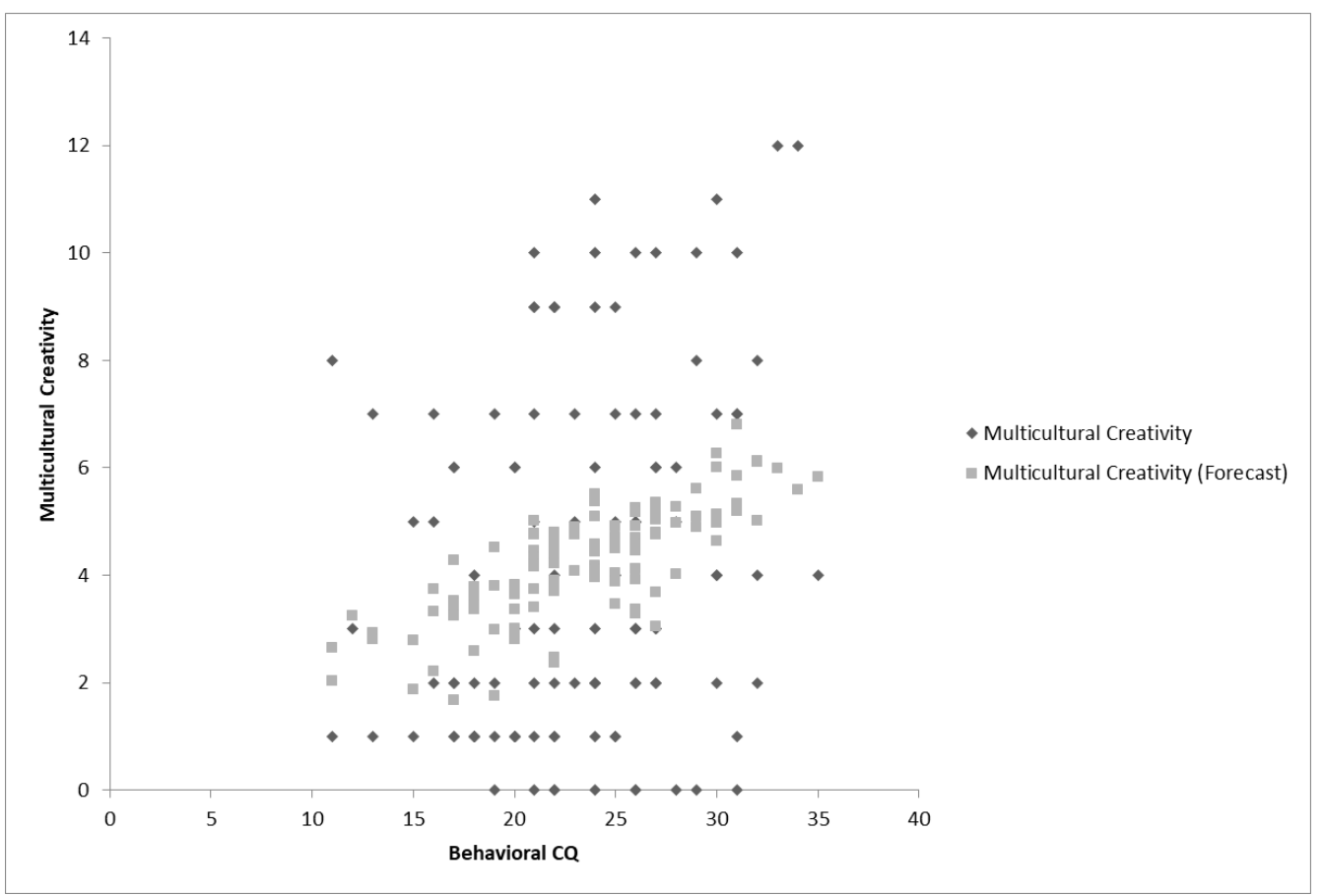

Figure 2. Adjusted Regression Curve for Behavioral CQ

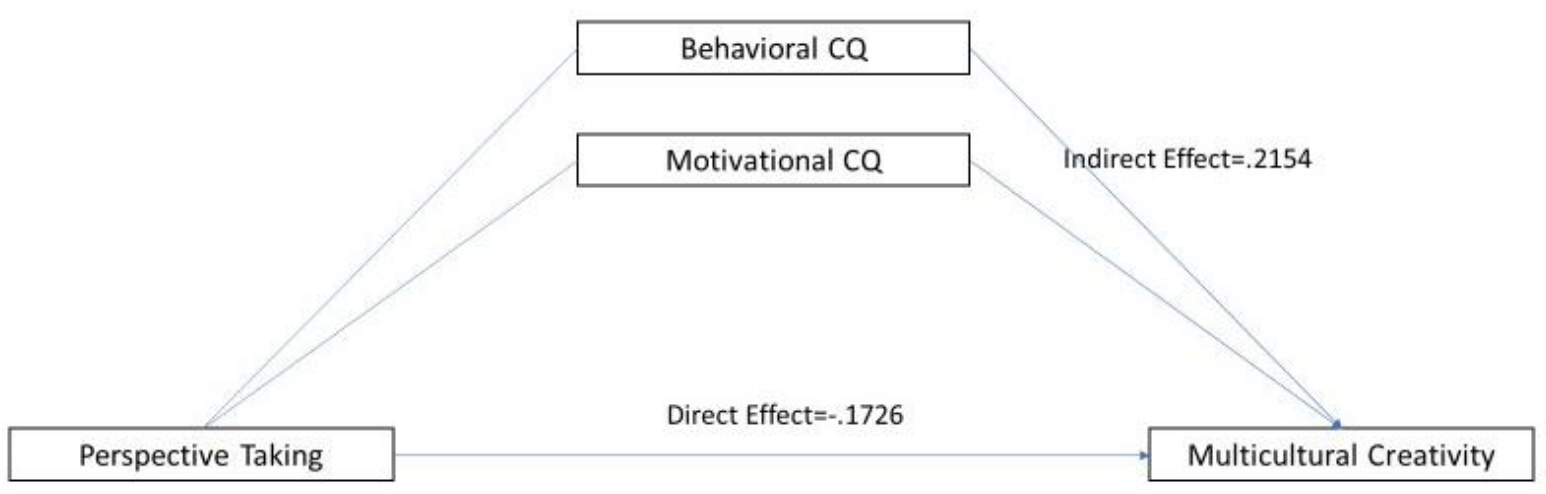

Figure 3. Behavioral CQ and Motivational CQ mediating effect on Perspective taking and Multic ultural creativity relationship

$* \mathrm{p}<.05$ Standardized coefficients

\section{Discussion}

This study of the relationship between cultural intelligence (CQ), perspective taking, and multicultural creativity presents three major contributions to the creativity and cultural intelligence literatures. First, it contributes to the resolution on how to mitigate the negative effects that multiculturally diverse environments may have on individuals' creativity. Second, it supports the use of cultural intelligence as a cultivable tool that enhances the development of creativity. Third, the findings constitute a novel approach to the four dimensions of cultural intelligence and their effect on the development of novel and useful ideas in multiculturally diverse environments.

However, limitations of the study emerge from the dispersion of participants in the sample which led to the impossibility to determine the multicultural environment climate and harmony. Hence, the measurement of the perceived degree of multiculturality within the respondents' immediate social surroundings did not provide an explanation for any of the other variables approached in this article. Future research may include the examination of pertinent variables such as trust and knowledge sharing within a multicultural setting, and to study their relationship with cultural intelligence. 
In summary, this study provides a major step toward cross-border collaboration in a world that is in vastly need of joint efforts to understand one another across nations and individuals.

\section{References}

Amabile, T. M. (1983). The social psychology of creativity: A componential conceptualization. Journal of Personality and Social Psychology, 45(2), 357-376. https://doi.org/10.1037/0022-3514.45.2.357

Ang, S., \& Van Dyne, L. (2006). Personality Correlates of the Four-Factor Model of Cultural Intelligence. Group \& Organization Management, 31(1), 100-123. https://doi.org/10.1177/1059601105275267

Ang, S., Van Dyne, L., Koh, C., Ng, K. Y., Templer, K. J., Tay, C., \& Chandrasekar, N. A. (2007). Cultural Intelligence: Its Measurement and Effects on Cultural Judgment and Decision Making, Cultural Adaptation and Task Performance. Management and Organization Review, 3(3), 335-371. https://doi.org/10.1111/j.1740-8784.2007.00082.x

Bhagat, R. S. (2006). Cultural intelligence: Individual interactions across cultures; Working Across Cultures. The Academy of Management Review, 31(2), 489-502. https://doi.org/10.5465/AMR.2006.20208695

Bücker, J. J. L. E., Furrer, O., \& Lin, Y. (2015). Measuring cultural intelligence (CQ): Anew test of the CQ scale. International Journal of Cross Cultural Management, 15(3), 259-284. https://doi.org/10.1177/1470595815606741

Bücker, J. J. L. E., Furrer, O., Poutsma, E., \& Buyens, D. (2014). The impact of cultural intelligence on communication effectiveness, job satisfaction and anxiety for Chinese host country managers working for foreign multinationals. International Journal of Human Resource Management, 25(14), 2068-2087. https://doi.org/10.1080/09585192.2013.870293

Černe, M., Nerstad, C. G. L., Dys vik, A., \& Škerlavaj, M. (2014). What goes around comes around: Knowledge hiding, perceived motivational climate, and creativity. Academy of Management Journal, 57(1), 172-192. https://doi.org/10.5465/amj.2012.0122

Chen, M. L., \& Lin, C. P. (2013). Assessing the effects of cultural intelligence on team knowledge sharing from a socio-cognitive perspective. Human Resource Management, 52(5), 675-695. https://doi.org/10.1002/hrm.21558

Chua, R. Y. J. (2013). The costs of ambient cultural disharmony: Indirect intercultural conflicts in social environment undermine creativity. Academy of Management Journal, 56(6), 1545-1577. https://doi.org/10.5465/amj.2011.0971

Cornell University, INSEAD, \& WIPO. (2016). The Global Innovation Index 2016 Winning with Global Innovation. Stronger Innovation Linkages for. https://doi.org/978-2-9522210-8-5

Daher, N. (2015). Emotional and Cultural Intelligences as an assessment tool for Recruiting, Selecting and Training Individual Candidates. International Journal of Business and Public Administration, 12(1), 167-181.

Davis, M. H. (1983). Measuring individual differences in empathy: A multidimensional approach. Journal of Personality and Social Psychology, 44(1), 113-126. https://doi.org/10.1037/0022-3514.44.1.113

Erez, M., Lisak, A., Harush, R., Glikson, E., Nouri, R., \& Shokef, E. (2013). Going Global: Developing Management Students' Cultural Intelligence and Global Identity in Culturally Diverse Virtual Teams. Academy of Management Learning \& Education, 12(3), 330-355. https://doi.org/10.5465/amle.2012.0200

Galinsky, A. D., \& Moskowitz, G. B. (2000). Perspective-taking: Decreasing stereotype expression, stereotype accessibility, and in-group favoritism. Journal of Personality and Social Psychology, 78(4), 708-724. https://doi.org/10.1037/0022-3514.78.4.708

Goodman, L. A. (1961). Snowball Sampling. The Annals of Mathematical Statistics, 32(1), 148-170. https://doi.org/10.1214/aoms/1177705148

Grant, A. M., \& Berry, J. W. (2011). The necessity of others is the mother of invention: Intrinsic and prosocial motivations, perspective taking, and creativity. Academy of Management Journal, 54(1), 73-96. https://doi.org/10.5465/amj.2011.59215085

Hargadon, A. B., \& Bechky, B. A. (2006). When Collections of Creatives Become Creative Collectives: A Field Study of Problem Solving at Work. Organization Science, 17(4), 484-500. https://doi.org/10.1287/orsc.1060.0200 
Hoever, I. J., Van Knippenberg, D., Van Ginkel, W. P., \& Barkema, H. G. (2012). Fostering team creativity: Perspective Taking as Key to Unlocking Diversity's Potential. Journal of Applied Psychology, 97(5), 982-996. https://doi.org/10.1037/a0029159

Jehn, K. A., \& Mannix, E. A. (2001). The dynamic nature of conflict: Alongitudinal study of intragroup conflict and group performance. Academy of Management Journal, 44(2), 238-251. https://doi.org/10.2307/3069453

Leung, A. K. Y., Maddux, W. W., Galinsky, A. D., \& Chiu, C. yue. (2008). Multicultural Experience Enhances Creativity: The When and How. American Psychologist, 63(3), 169-181. https://doi.org/10.1037/0003-066X.63.3.169

Livermore, D., Ang, S., \& Van Dyne, L. (2010). Leading with Cultural Intelligence. Retrie ved from file:///Users/jeffprice/Downloads/Livermore2010-Leading_with_Cultural_Intelligence.pdf

Maddux, W. W., Adam, H., \& Galinsky, A. D. (2010). When in rome ... learn why the romans do what they do: How multicultural learning experiences facilitate creativity. Personality and Social Psychology Bulletin, 36(6), 731-741. https://doi.org/10.1177/0146167210367786

Ng, K. Y., Ang, S., \& Van Dyne, L. (2011). Speaking up in the culturally diverse workplace: The role of cultural intelligence and language self-efficacy. American Psychological Association.

Sessa, V. I. (1996). Using perspective taking to manage conflict and affect in teams. Journal of Applied Behavioral Science, 32(1), 101-115. https://doi.org/10.1177/0021886396321007

Van Dyne, L., Ang, S., \& Koh, C. (2008). Development and Validation of the CQS. Handbook of Cultural Intelligence: Theory, Measurement, and Applications. Retrieved from http://books.google.com/books?hl=en\&lr=\&id=FSTzFksL0IkC\&pgis=1\%5Cnhttp://books.google.com/boo ks?hl=en\&amp;lr=\&amp;id=FSTzFksL0IkC\&amp;oi=fnd\&amp;pg=PR5\&amp;dq=Handbook+of+cultural +intelligence:+theory,+measurement,+and+applications\&amp;ots=39NMOaElvy\&amp;

Vovchenko, N. G., Ivano va, O. B., Kostoglodova, E. D., Otrishko, M. O., \& Dzhu, O. S. (2016). Innovations and Fighting Global Economic Problems. Contemporary Economics, 10(4), 289-298.

https://doi.org/10.5709/ce.1897-9254.216

\section{Copyrights}

Copyright for this article is retained by the author(s), with first publication rights granted to the journal.

This is an open-access article distributed under the terms and conditions of the Creative Commons Attribution license (http://creativecommons.org/licenses/by/4.0/). 